\title{
"BEING WHAT ONE OUGHT TO BE": \\ ENGLISH AS A LINGUA FRANCA IN THE ACADEMIC SPOKEN DISCOURSE OF BULGARIAN AND GERMAN STUDENTS
}

\author{
Emilia Slavova
}

\begin{abstract}
In an age of globalization and super-diversity, the concept of English as a national, homogeneous entity has been seriously undermined, and non-native speakers have been encouraged to use the language without constant recourse to the native-speaker ideal. Yet different varieties of English have different value attached to them on the linguistic market, in Bourdieu's terms; and non-native speakers are in possession of different linguistic capital. The paper focuses on the relationships and attitudes to English on behalf of Bulgarian and German university students participating in a joint project in which a corpus of academic spoken English is compiled. Alongside collecting the corpus, the project appears to have a positive educational outcome in that it raises awareness about the specificity of English as a lingua franca.
\end{abstract}

\section{Keywords}

English as a lingua franca, non-native speakers, academic discourse, computer-mediated discourse, linguistic capital, super-diversity

\section{Introduction}

Learners of English today have the advantages of increased mobility, greater international contacts, and much greater access to authentic sources of English compared to previous generations. In an age of "globalization, superdiversity and multilingualism" (Blommaert 2010: 6) English has developed as an international language, and has, in the process, been transformed in various ways. The concept of English as a national, monolithic, homogeneous entity has been seriously undermined, and non-native speakers have been encouraged to use the language without constant recourse to the native-speaker ideal, ardently upheld in previous decades.

This paper focuses on the relationships and attitudes to English on behalf of Bulgarian and German university students involved in non-native speaker computer mediated communication (CMC). What is of interest to me are the speakers' subjective evaluations of their own and their interlocutors' performance, and in particular their being at ease with themselves, of "being what one ought 
to be" (Bourdieu 1993: 85) while speaking English. In Bourdieu's terms, those in possession of linguistic capital, defined as the control over what is appropriate verbal social behaviour, can revel in the feeling of confidence and ease, while the feelings experienced by the aspirant groups are described as "timidity, tension, hypertension; they always do too much or too little, they are ill at ease with themselves" (ibid.). Another point of interest is to observe to what extent the idea of English as a lingua franca has been internalised by the Bulgarian students and how ready they are to move away from the traditional view of English as belonging to the native speakers.

The analysis is based on the Corpus of Academic Spoken English (CASE Sofia Saarbrucken). The project involves around $120 \mathrm{CMC}$ between 25 German and 14 Bulgarian university students of English, held via Skype. The conversations are roughly an hour long, with students changing partners and discussing ten to twelve previously assigned topics. For the current analysis, I have used ten of the transcriptions in which the conversations touch upon language-related issues (not all of the recordings have been transcribed yet), as well as 13 reflective essays of the Bulgarian students participating in the project. The transcripts are given in their original form and have not been edited for language mistakes.

A point worth making at this stage is that participating in an educational project of this kind puts the students in a mixed communicative situation. On the one hand, they are free to express themselves in front of their peers in the comfort of their own home, in front of their PC, while on the other hand, they are constrained by the awareness that their conversations are being recorded and are likely to be listened to by their teachers, as well as by many other people. This fact makes the distinction between users of ELF and learners of English, drawn by Mauranen (2012: 4), rather blurred. In this particular situation, the students are both learners participating in an educational project and users of English as a lingua franca, especially when they forget about the project and get carried away by the spontaneous communication with peers.

\section{English as a lingua franca}

Let me first briefly discuss the term English as a lingua franca. ELF is one of several terms used with reference to the way the English language has developed in recent years. Similar terms are English as an international language, English as a global language, English as a world language, World English, or the plural form World Englishes (referring to the multitude of now indigenized varieties of English in the former British colonies). The terms, while to an extent overlapping, reflect different aspects of the status of English as an international language and its different uses by native speakers from the Inner and Outer circles, or between speakers from the Expanding circle, in Kachru's terms (Kachru 1992). 
ELF focuses on the English language as used primarily by speakers who do not share the same mother language and culture; a "contact language" which "has reached truly global dimensions, and as a consequence, is being shaped, in its international uses, at least as much by its non-native speakers as its native speakers" (Seidlhofer 2004: 211). In addition, the process has been accelerated by the dramatic growth of electronic communication; there is also an ongoing process of destandartization, based on the fact that English is used by many people whose lexis, grammar and pronunciation do not conform to any recognized norm (ibid.). A reconceptualization of ELF, according to Seidlhofer, would focus on the following factors:

- Questioning of the deference to hegemonic native-speaker norms in all contexts;

- Emphasizing the legitimacy of variation in different communities of use;

- Highlighting the need to pursue the attitudinal and linguistic implications of the global spread of English;

- Acknowledging the need for description and codification (Seidlhofer 2004: 214).

Such a conceptualization seems adequate and fair to the description of communication between non-native speakers. The question is how far the speakers themselves are aware of the concept of ELF and its implications for intercultural communication in English; how much the concept of ELF allows them to feel 'at ease' with themselves as English language speakers.

\section{The status of English as a foreign language in Bulgaria}

Before I discuss the collected data and try to answer the above questions, let me briefly sketch the status of English as a foreign language in Bulgaria. Before the fall of the Iron Curtain, when Bulgaria was part of the Eastern bloc, international communication was mostly between the countries within its realm, and Russian was the main lingua franca. However, after the fall of the communist regime in Bulgaria in 1989, Bulgaria opened up to the Western world and English quickly gained a prominent role, displacing Russian in the educational system and becoming the main foreign language. The Bulgarians gained the right to travel freely, although financial and other limitations are still an inhibiting factor. Unlike in previous years, there is now easy access to English-speaking media channels. The digital revolution has further facilitated communication with the Western world, and students have much easier access to authentic models of English, compared to previous decades.

Unlike in many other parts of the world, where English still carries a heavy legacy of being an imperialist language forcibly imposed on the local population 
and displacing indigenous languages and cultures, in Bulgaria it was seen by many as the language of progress, democracy and freedom; as Georgieva observes, "Inspired by the ideals propagated by the electronic mass media, the music and film industries, most learners, especially adolescents, long to break away from local traditions and rigid standards of education, and perceive English as a symbol of freedom and openness to the democratic values of the rich western countries" (Georgieva 2002: 150). English is also the language of opportunity, providing access to jobs, education, travelling and information which may be hard to obtain otherwise. In this sense, mastery of English very clearly symbolizes linguistic capital, in that it gives its speakers a communicative advantage, access to western culture, and a certain sense of superiority.

At the level of language policy and language pedagogy, English has become the main foreign language, taught in most schools and usually displacing the previous main foreign language, Russian. There is a strong tendency to teach English as a national language, either associated with British or American culture, and not much has been done yet to focus on its current international status and features. Instead, language teaching in Bulgaria has kept a fine balance between British and American English. As O'Reilly observes, both varieties have their historical roots in Bulgarian education, as well as the active support of presentday cultural institutions such as the British Council and the Peace Corps, and co-exist in a "linguistic sibling rivalry" (O'Reilly 1998: 71). This dual influence is evident to the present day, albeit not as strongly perhaps as in the early days after the fall of the Iron Curtain.

Besides, language teaching in Bulgaria has tended towards formal schooling, with more emphasis on the teaching of grammar, vocabulary and a focus on accuracy, often at the expense of communication and fluency. This further reinforces the tendency to teach English from a prescriptivist position, focusing mainly on the standard variety.

\section{Bulgarian-German discussions about ELF}

The analysis of a sample of the Bulgarian and German conversations reveals that the students participating in the project are well aware of the importance of English for international communication today, as seen from this excerpt (SB stands for the German students from Saarbrucken University and SF stands for the Bulgarian students from Sofia University; the numbers refer to their unique identification numbers):

SB21: I don't know really how many languages they have to speak but uhm, I mean there is no way around English I guess 
SF03: oh, it's becoming a global language

SB21: yeah

SF03: everybody in the [world knows it]

SB21: [yeah]

SF03: before it used to be Russian I think

SB21: (( $\mathrm{mm}))$

SF03: children learned Russian in school as a global language and now it has become English

Both students agree on the status of English as a global language. What is interesting here is that the Bulgarian student refers to Russian as a global language spoken in the period before the student was born (Russian was an international language for the Eastern bloc, but not a global language in the sense that English is), while the German student does not contradict this statement, although he probably does not support this point of view.

The conversation continues with comments on both participants' English proficiency and mutual compliments about their linguistic abilities. The German student expresses surprise at the Bulgarian student's mastery of the language and the fact that he has mastered it without having been to an English speaking country:

SB21: [so this] this is only your second year of studies

SF03: yeah, I'm still a bachelor ((chuckle))

SB21: okay but your English is really nice [so that - I mean]

SF03: [thank you]

SB21: [yeah, have you been-]

SF03: [likewise]

SB21: [have you been to England?]

SF03: $n o$

SB21: no?

SF03: not yet

at least I really want to go there

but I haven't been there (at least)

[but uhm-]

SB21: [but how have you]

how have you learned English then

I mean just at school, university or

SF03: ((chuckle))

well uhm uh you remember cartoon network

before its- they bought it

I mean they've changed it a lot when ... 
SF03: well you have a-

a very nice pronunciation

I mean really

not just returning the compliment

It's really clear

and you could understand it easy

The fact shared by the Bulgarian student is typical for most of the first and second year students at the Department of English and American Studies at Sofia University. Most of them have had little international exposure in the first year. (Erasmus and Work-and-Travel programmes allow them to travel to Europe and the USA after their first year and some of them take this opportunity.) In contrast, the German counterpart has been to both Britain and the USA and shares observations about the different accents he has observed in both places.

The explanation the Bulgarian student gives for his good command of English is one often encountered in the Bulgarian students' accounts of how they learned to speak English: Cartoon Network $(\mathrm{CN})$. In spite of my initial reserve about this source, it seems to have given many students not only passive knowledge of English but has also contributed to their imitating the accents they hear on television. As a result, many of them may sound more fluent than their teachers, whose English has been formed mostly via formal schooling. In the face of limited native speaker teachers of English, CN seems to have fulfilled an important function which previous generations of learners of English in Bulgaria did not have; and what is particularly important is that this channel has apparently reached children from an early age, when they are most susceptible to acquiring languages and are also prone to spending long hours in front of the TV.

In another conversation, the Bulgarian student receives a compliment about his English but shows extreme high-consciousness and self-criticism, commenting that as a first-year student ('first course', interference from Bulgarian) he should be able to speak good English. His lack of confidence is also felt in the hesitations and interruptions in his speech:

SB03: and I think you can speak really well English

SF06: $o h$..

((laugh))

this is very nice to hear... and ((cough))

but I think tha-that's uh...

for first course...

I should be able to talk like that

I mean uh.. I am worse than you think... 
A discussion about native and non-native teachers in both universities between the same pair of students reveals that the Bulgarian students at Sofia University have few native speakers of English (one Irish speaker, who teaches one or two of the groups, not all of them).

SB03: and uhm... are your English teachers all native speakers

SF06: oh, uhm.. no.. they are not and they are Bulgarians but I think uhm... that one of the group one of the groups or maybe two of the groups uh... they have a native speaker... who is Irish... uhm... but I haven't been $u h$... on his courses and... I think that uh... even though they are not native speakers... my teachers ... my lecturers... are really good at English and uh... they can teach me... how to be confident in speaking...

While the last comment makes a very positive statement about Bulgarian teachers, it is good to remember that the students are well aware that their conversations will be monitored by their teachers and may not want to sound negative about them.

A similar discussion on the same topic reveals that the German students have a much wider access to native speakers, and a choice between different native varieties of English.

SB 09: and in my uh in my English department like in my university... we have a lot of native speakers so we have uhm... lots of teachers from Great Britain... or from the US... so uhm... because in...

in our department they often differentiate between...

American English or uh... British English and you know like...

if you want or if you like to focus on...

one of these uhm... accents

you can go to different teachers

SF06: $o h \ldots$

SB09: but of course we also have German teachers but we have..

I think the majority of our teachers are native speakers

In another conversation, a Bulgarian student discusses how the feelings experienced regarding speaking English to a foreign student have changed over the course of the project. It seems that the Bulgarian student has overcome the 
initial unease and discomfort, as well as the mistakes made because of high levels of anxiety:

SF06: I am starting to... uh... I'm not so... depressed and confused...

and I can now tel-talk to you freely.. and

while in the... during my first conversation... I was really excited

SB18: [nervous]

SF06: and nervous...

SB18: yeah

SF06: and uh... I uh made a lot of mistakes... which are ... not because I don't know them ... but...

SB18: yeah

SF06: because I'm so nervous... and cannot think of anything...

The analysis of Bulgarian-German student computer-mediated encounters clearly indicates certain asymmetries in the resources available for acquiring English from direct contacts with native speakers, as well as feelings of tension and anxiety shared by some of the Bulgarian students (no indication of the German students' feelings, either positive or negative, were observed in the analysed recordings).

\section{Bulgarian students' reflections on ELF}

The reflective essays written at the end of the project by the Bulgarian students shed further light on the comparisons between the two groups. While the students have not been given any prior information about the concept of ELF, they have been able to make their own conclusions about it based on their personal experiences. On the basis of the conversations held with their German colleagues, they make observations on cultural differences in their relationship to English, their different access to native-speaker English, and their changing confidence as a result of the project.

Although not a typical topic of discussion in the students' essays, one student shows a clear understanding of the status of English as an international language and underscores its development as a lingua franca as her main motivation to participate in the project:

It is a common fact that English has somewhat exceptional status among other languages. It is the language that most people who don't share a common native tongue resort to (unless of course one of the two speaks the native language of the other). My interest in the dynamics of the development of English as a lingua franca is what made me participate in the project. 
An interesting observation she makes concerns the importance of English to the Bulgarians and to the Germans respectively. While the Bulgarians are well aware of the fact that their language is a minor language of little international importance and that learning English is crucial for successful career development, both in the country and abroad, Germans have a more relaxed attitude to learning English because they realize that German has much greater international importance:

... I realized that English is much more important to Bulgarians than to Germans (and here I mean not the students of English in the two countries but rather the nations as a whole). Bulgarian is not a popular language worldwide and that is why for Bulgarians it is a must to know English if they want to find a good job. English is a requirement in virtually every job advertisement in Bulgaria. German on the other hand is a popular language worldwide and so Germans are more relaxed about the connection between foreign languages and finding a job.

At the same time, the German students participating in the project seem to have had much greater opportunities to learn English in an English-speaking environment or with the help of native speakers of British or American English. This has not only helped them to learn the language to a high level, but also to feel more confident and relaxed about speaking it. They also feel more comfortable communicating with people from other countries, while the Bulgarian students have had less experience talking to people outside of Bulgaria (I sometimes have students who admit to having never spoken to foreigners in their life), and this also affects their confidence in using English in intercultural encounters:

All of my partners have been to an English-speaking country and sounded comfortable while talking. I, on the other hand, could catch myself making mistakes at times and the more technological and Internet obstacles there were, the more mistakes I made.

Another student remarks that each of their German counterparts "speaks English very well and has an RP accent", and many of them are preparing to become teachers of English soon. The German students are in their final year of studies and close to graduation, while the Bulgarians are predominantly in their first year of study (only one of them is a third-year student). This, according to the Bulgarians, means that the Germans are much more experienced than the Bulgarians, both academically and socially (one of the German students even has two children). As a result, the Bulgarian student shares that "At times I felt inexperienced due to the age difference." 
Another group of observations the Bulgarian students make concerns the communication strategies used by both sides. One student observes that "both Bulgarians and Germans tend to use strange structures when they have to express their thoughts in English"; they translate literally from their mother tongue, yet both sides manage to understand each other. Another student observes that both sides tend to simplify the language used and limit their vocabulary in order to achieve better understanding:

The last thing I want to note is that when we spoke, we usually used a very limited range of vocabulary probably because we wanted to sound as natural and clear as possible. Of course we would have understood each other with more advanced expressions but both me and any of my partners talked in a simple way with simple constructions and words.

In addition, the same student attests to both sides converging towards each other's communicative style and echoing each other's expressions in order to improve mutual understanding:

What's more, we started using a particular word after we had heard it from the other partner - if I tend to use a specific collocation, e.g. "achieve a goal", and the partner uses "reach a goal", I would start also saying "reach a goal" more frequently. I could notice the same tendency with my German partners.

As a result of their participation in the project, the Bulgarian students generally report having overcome their initial feelings of unease and apprehension in speaking to foreigners, as well as their linguistic performance:

At the beginning I felt quite unprepared because I had not talked to many foreign people in English. That is why I made many mistakes and was worried and nervous. It took me some time to become more confident and start talking to my Skype partners more openly.

The students also share that in the course of the project they have developed greater confidence and are less concerned about making mistakes, in comparison to earlier periods when they have felt very careful and "too conscious of following strictly the standard linguistic rules":

I got the impression that I felt more comfortable to speak with mistakes and didn't feel that worried when I had difficulties in expressing myself or understanding my partners. 
Finally, one student provides a good summary of the above observations and discusses how taking part in the project has freed him from embarrassment, making comments about the role of English as a global language shortening the distances between people and enhancing communication between them:

The course gave me a lot in terms of freeing myself from any embarrassment or nervousness, having in mind how difficult it was for me to speak English with foreign speakers. I love the way the global language gives people the opportunity to cut the distances between them and communicate much easier.

\section{Discussion}

The above comments and observations of Bulgarian and German university students of English participating in the Corpus of Academic Spoken English project have touched upon several important aspects of the use of English as a lingua franca. First of all, the expectations about a power imbalance between the speakers have been confirmed to a certain extent. The German speakers in the project are not only more privileged in that they have had more opportunities to learn English with the help of native speakers and to practise speaking it in English-speaking countries; they also happen to be more advanced in their academic studies than their Bulgarian counterparts, more experienced academically and socially. In addition, English is a Germanic language, while Bulgarian is a Slavonic language, which makes it more distant linguistically from English and therefore more difficult for the Bulgarians to learn. The Germans, on the whole, seem to be in possession of greater linguistic capital, as well as other kinds of symbolic capital, as compared to the Bulgarians in the project.

However, the analysed conversations and the reflective essays do not show any clearly pronounced power relations between the two groups of students. On the contrary, the fact that the Bulgarian students report greater ease and comfort in their use of English towards the end of the project can be interpreted as a sign that the conversations have helped them to overcome their perceived linguistic deficiencies and have empowered them to see themselves as competent language users. This may be the result of the friendly tone of the conversations, as well as the fact that the German students do not exploit the objective power differences to their advantage, but strive to maintain harmonious relationships.

The reported feeling of freedom from embarrassment and nervousness is indeed a very valuable outcome of this project, and one that may not have been calculated initially. The project's main focus may have been on collecting a corpus of non-native spoken English, but it has obviously had important educational implications as well. The students have not only improved their spoken language, 
but have developed greater confidence and an increased awareness of some features of ELF: simplified language, convergence towards the language of the conversational partner, greater tolerance towards deviations from native speaker norms, focus on intelligibility rather than correctness, developing interaction strategies that promote comity, better communication skills, and probably also better intercultural skills.

The second part of the project, involving students in the transcription of the conversations (with clear instructions and a final editing by teachers) has further increased their awareness of the discrepancy between what is considered to be standard, written language and the difficulty of adequately translating spoken language into a written code. There seems to be no end to the level of detail one can observe and record when transcribing, and a focus on ELF further requires for deviations from the norm at every level to be recorded, as well as many paralinguistic features of discourse, pauses, laughter, overlaps, interruptions, and so on. This allows students to appreciate the richness of language, its multimodality, and its boundless variation.

An extension of the project could involve asking students to write papers using the corpus and looking for specific features of ELF. The fact that they or their colleagues have participated in the project would certainly contribute to their interest in exploring the corpus, and will help them make connections between theoretical concepts and real-life experiences.

Projects like this certainly have great potential for experiential learning about the role of English today; for questioning the hegemony of the native-speaker norms, for emphasizing the legitimacy of variation, for highlighting the need to reassess the high value attached to Standard English in the face of growing super-diversity and heteroglossia. "Abandoning unrealistic notions of achieving perfect communication through 'native-like' proficiency in English would free up resources for focusing on capabilities that are likely to be crucial in ELF talk", Seidlhofer maintains (2004: 226).

Such projects could also help students reassess certain long-held views in linguistics and become aware of major changes and 'paradigm shifts' being brought about in recent years:

Over a period of several decades - and often emerging in response to issues predating super-diversity - there has been ongoing revision of fundamental ideas (a) about languages, (b) about language groups and speakers, and (c) about communication. Rather than working with homogeneity, stability and boundedness as the starting assumptions, mobility, mixing, political dynamics and historical embedding are now central concerns in the study of languages, language groups and communication (Blommaert \& Rampton 2011: 4). 


\section{Conclusion}

To sum up, as a result of studying the conversations and the reflective essays of students involved in the CASE project, I am convinced that the project has proven to have not only research value, but also significant educational value for the students involved. The analysed conversations and reflections show the value of raising students' awareness about the concept of English as a lingua franca: a variety without native speakers, and with greater tolerance towards deviations from Standard English. While teaching Standard English needs to continue, as it is often required in formal contexts, examinations and other situations, it is highly beneficial to students to be acquainted with other varieties of English and to develop fluency, confidence, the feeling of ease and 'being what one ought to be', even if they do not closely follow native-speaker models.

\section{References}

Blommaert, J. (2010) The Sociolinguistics of Globalization. Cambridge: Cambridge University Press.

Blommaert, J. and Rampton, B. (2011) 'Language and superdiversity: A position paper.' In: Working Papers in Urban Language and Literacies. Online document. http://www. $\mathrm{kcl}$.ac.uk/sspp/departments/education/research/ldc/publications/workingpapers/70. pdf, retrieved January, 2014.

Bourdieu, P. (1993) Sociology in Question. London: Sage.

Georgieva, M. (2002) 'On developing intercultural communicative competence in EFL learners.' In: Thomas, D. and Georgieva, M. (eds) Smaller Languages in the Big World. British Council Bulgaria. 146-159.

Kachru, B. (1992) The Other Tongue: English Across Cultures. University of Illinois Press.

Mauranen, A. (2012) Exploring ELF. Academic English Shaped by Non-Native Speakers. Cambridge: Cambridge University Press.

O'Reilly, L. (1998) 'English language cultures in Bulgaria: A linguistic sibling rivalry?' World Englishes 17/1, 71-84.

Seidlhofer, B. (2004) 'Research perspectives on teaching English as a Lingua Franca.' In: Annual Review of Applied Linguistics 24. Cambridge: Cambridge University Press. 209-239.

\section{Source}

Corpus of Academic Spoken English Sofia Saarbrucken, to be made available online at http://www.uni-saarland.de/lehrstuhl/engling.html 